\title{
İrritabl Bağırsak Sendromu Olan Hastalarda Beslenme Durumunun İncelenmesi
}

\author{
Investigation of Nutrition Status in Patients with Irritable Bowel Syndrome
}

\author{
Ecem ALTINOK ${ }^{1}$ (iD), Eda AYDIN ${ }^{1}$ (iD), Süeda KOVAL ${ }^{1}$ (iD, Ayşegül İpek ÖZBIILGİN ${ }^{1}$ (iD), Burcu ŞENER ${ }^{1}$ (iD, \\ Öznur Özge ÖZCAN ${ }^{2}$ (D), Hatice ÇOLAK ${ }^{1}$ (D), Esra Tansu SARIYER ${ }^{1}$ (D), Ekin ÇEVIIK ${ }^{1}$ (D), Mesut KARAHAN ${ }^{2}$ (D)
}

ÖZ

İrritabl bağırsak sendromu, abdominal ağrı, gaz, şişkinlik ve bağırsak alışkanlığının değişmesi ile karakterize kronik fonksiyonel bir gastrointestinal bozukluktur. Çeşitli diyet yaklaşımları ve beslenme alışkanlıkları hastalığın semptomlarıyla ilişkili olabilmektedir. Bu çalışmanın amacı, irritabl bağırsak sendromu bulunan hastaların beslenme alışkanlıklarının incelenmesi ve sağlıklı bireylerin beslenme alışkanlıkları ile karşılaştırılmasııdır. Bu amaçla, çalışmaya Mart-Nisan 2020 tarihleri arasında online erişim ile gerçekleştirilen çalışmaya Roma IV kriterlerine göre irritabl bağırsak sendromu tanısı almış 40 hasta ile sağlıklı 40 kontrol alındı. Bireylerin demografik özellikleri, beden kitle indeksi, beslenme alışkanlıkları ve besin tüketim sıklığına ilişkin veriler anket formu ile topland1. Veriler SPSS 25.0 Programı ile analiz edilerek istatistiksel anlamlılık için $\mathrm{p}<0,05$ değeri kabul edildi. Çalışmaya katılan hastaların \%80'i kadın ve beden kitle indeks ortalaması $24,73 \pm 3,88 \mathrm{~kg} / \mathrm{m}^{2}$ ve irritabl bağırsak sendromu tanıs1 konma süresi ortalama $6,15 \pm 6,83$ yıl olarak saptandi. Sağlıklı bireylerle karşılaştırıldığında hastaların yaş ve beden kitle indeksi anlamlı olarak daha fazla bulundu $(\mathrm{p}<0,05)$. Hastaların $\% 17,5$ 'i probiyotik tüketirken; sağlıklı bireylerin hiçbirinin tüketmediği belirlendi, aradaki fark anlamlı bulundu $(\mathrm{p}<0,05)$. Hastalık tanısı alma durumuna göre et, balık ve tavuk; ekmek, tahıl ve kuru baklagiller; yumurta tüketimi arasındaki farklar anlamlı bulundu $(\mathrm{p}<0,05)$. Sonuç olarak, irritabl bağırsak sendromu olan hastalar, sağlıklı bireylere göre, semptomları tetikleyecek besinleri tüketmemeye eğilimli iken; probiyotik kullanımı gibi semptomları hafifletebilecek davranışlar sergilemektedir. Buna göre, irritabl bağırsak sendromu tedavisinde sağlıklı beslenme alışkanlıkları edinmek hastalığın prognozunu olumlu etkilemektedir.

Anahtar Kelimeler: İrritabl bağırsak sendromu, Beslenme, Obezite, Probiyotik

Ecem ALTINOK, Eda AYDIN, Süeda KOVAL, Ayşegül İpek ÖZBİLGIN, Burcu ŞENER, Hatice ÇOLAK, Esra Tansu SARIYER, Ekin ÇEVIK Üsküdar Üniversitesi, Sağllk Bilimleri Fakültesi, Beslenme ve Diyetetik Bölümü, İstanbul

Öznur Özge ÖZCAN, Mesut KARAHAN (丣)

Üsküdar Üniversitesi, Sağllk Bilimleri Enstitüsü, Moleküler Nörobilim Bölümü, İstanbul

e-mail: mesut.karahan@uskudar.edu.tr

\begin{abstract}
Irritable bowel syndrome is a chronic functional gastrointestinal disorder characterized by abdominal pain, bloating, distension and altered bowel habits. Some dietary approaches and eating habits may be associated with the symptoms of the disease. The aim of the study is to examine the eating habits of patients with irritable bowel syndrome and to compare them with the eating habits of healthy individuals. For this purpose, 40 patients diagnosed with irritable bowel syndrome according to Rome IV criteria and 40 healthy controls were included in the study, which was conducted online between March and April 2020. Data on demographic characteristics, body mass index, nutritional habits and frequency of food consumption of individuals were collected with a questionnaire form. The data were analyzed with SPSS 25.0 program and $\mathrm{p}<0.05$ was accepted for statistical significance. $80 \%$ of the patients participating in the study were female and the average body mass index is $24.73 \pm 3.88 \mathrm{~kg} / \mathrm{m}^{2}$ and the duration of diagnosis of irratable bowel syndrome is $6.15 \pm 6.83$ years on average. Age and body mass index of the patients are significantly higher $(p<0.05)$ compared to healthy individuals. While $17.5 \%$ of the patients consumed probiotics; it was determined that none of the healthy individuals consumed; the difference was found to be significant $(\mathrm{p}<0.05)$. According to the disease diagnosis, difference between of meat, fish and chicken; bread, cereals and legumes; egg consumption was statistically significant $(\mathrm{p}<0.05)$. In conclusion, avoiding foods that may bother these patients from the diet and using probiotics can alleviate irritable bowel syndrome symptoms. Accordingly, adopting healthy eating habits positively affects the prognosis of the disease in the treatment of irritable bowel syndrome.
\end{abstract}

Keywords: Irritable bowel syndrome, Nutrition, Obesity, Probiotic

\section{GİRiş}

En sık teşhis edilen gastrointestinal hastalıklardan biri olan irritabl bağırsak sendromu (IBS), abdominal ağrı, gaz, şişkinlik ve bağırsak alışkanlığının değişmesi ile karakterize kronik fonksiyonel bir gastrointestinal bozukluktur. IBS tanısı konması için Roma IV kriterlerine göre; önceki 3 
ay içinde haftada en az 1 gün tekrarlayan abdominal ağrı görülmesi ve bu ağrının dışkılama, dışkı sıklığı ve dışk1 biçiminde (görünüm) bir değişiklik ile ilişkilendirme semptomlarından iki veya daha fazlasının bulunması gerekmektedir (1).

IBS prevalans1 genel popülasyonun \%5-20'sini etkilemektedir ve sıklıkla 18-34 yaş grubunda görülmektedir (2). Oka ve ark. yaptı̆̆ 1 sistematik bir derlemede, 42 farklı ülkede Roma III ve Roma IV kriterlerine göre tanı konan IBS hastalarının prevalansını inceleyen çalışmaları değerlendirmiştir (3). $\mathrm{Bu}$ değerlendirmeye göre, IBS prevalansının Roma III kriterleri kullanıldığında \%9,2 ve Roma IV kriterleri kullanıldığında $\% 3,8$ olduğu saptanmıştır. Türkiye'de yapılan popülasyon çalışmalarında IBS prevalansı \%6,3-19,1 arasında değişmektedir (4). Özer ve ark.'nın makalesinde, remisyon dönemindeki inflamatuar barsak hastalığı olan hastalarda Roma IV kriterlerine göre IBS semptomlarının sağlıklı kontrollere göre 2-3 kat daha yüksek olduğu, ancak hastaların yaşam kalitesinin daha düşük olduğunu belirtmiştir (5). Tanı kriterlerinden bağımsız olarak IBS'nin kadınlarda daha sık görüldüğü bilinmektedir (6). Batı ülkelerinde IBS görülme sıklığının kadınlarda, erkeklerden yaklaşık iki kat fazla olduğu tahmin edilmektedir (7). Ancak Asya ülkelerine bakıldığında tıbbi tedavi arayan IBS'li hastaların prevalansı erkeklerde daha yüksek bulunmuştur (8). IBS'li bireylerin rahatsız edici semptomların neden olduğu düşük yaşam kalitesi nedeni ile üretkenliği ve iş/okul günlerinde verimi azalmaktadır (7). Ayrıca IBS, birinci ve ikinci basamak sağllk hizmetlerinin maliyetlerini önemli düzeyde artırarak, olumsuz bir etkiye sahiptir (9).

IBS'nin patofizyolojisi karmaşıktır. Geçtiğimiz yıllarda patofizyolojiye katkıda bulunan farklı faktörler bulunmuştur (10). Bunlar arasında bağırsak immün aktivasyonu, artmış bağırsak geçirgenliği, değiştirilmiş mikrobiyota, düşük dereceli iltihaplanma, psikolojik faktörler ve besin intolerans1 yer almaktadır (11). IBS hastalarının çoğu, yiyecek alımının semptomların oluşmasına veya kötüleşmesine yol açtığını bildirmiştir (12). Bu hastalarda gluten, buğday, laktoz gibi makro besin intolerans1 ile fruktoz malabsorbsiyonu gibi beslenmeye ilişkin sorunların belirtilere neden olabileceği düşünülmektedir (13).

Son yıllarda çeşitli beslenme yaklaşımlarının IBS semptomlarını tedavi etmede etkili olduğu görülmektedir (12). Hastalarda bulunan IBS semptomuna göre uygulanacak beslenme tedavisi değişiklik gösterebilmektedir. Diyare varlığında az posalı; konstipasyon varlığında ise bol posalı beslenme önerilmektedir (14). Moayyedi ve ark. meta-analizinde, IBS hastalarında çözünür diyet posasının semptomları iyileştirdiği; çözünmeyen posanın ise etkili olmadığı görülmüştür (15). Çözünür posa, gastrointestinal yolda bağırsak bakterileriyle iletişime girmekte ve gastrointestinal geçişini kısaltabilen bir jel yapı oluşturmaktadır. Aksine, çözünmeyen posa, gastrointestinal kanalda hiç değişmemektedir. Yüksek miktarda çözünmeyen posa alımı ise su içeriğini ve dışkı hacmini artırdığından gastrointestinal geçiş süresini uzatmaktadır (16).

Fermente olabilen oligosakkaritler, disakkaritler, monosakkaritler ve polioller (FODMAP'lar) içeren besinler aşırı tüketildiğinde ince bağırsak içine su çekmekte ve mikrobiyota aracılı kolonik gaz üretimi artmaktadır. Buna bağlı olarak fermentasyon sonucu oluşan gaz, abdominal ağrı, diyare gibi IBS semptomlarına neden olmaktadır. IBS hastalarına uygulanan düşük FODMAP içeren diyet sonucunda abdominal ağrı, şişkinlik, gaz ve dışkı kıvamı gibi semptomlarda düzelme gözlenmiştir (17).

Probiyotikler, bağırsak mikrobiyal dengesini iyileştirerek konağa fayda sağlayan mikroorganizmalardır. Probiyotikler, gastrointestinal florayı modüle ederek IBS semptomlarının iyileştirilmesinde kullanılabilmektedir (18). Bir meta-analizde probiyotik kullanan hastalarda IBS semptomlarının kalıcılığı, plaseboya göre daha düşük bulunmuştur. Ancak çok suşlu probiyotik takviyelerinin IBS semptomlarını iyileştirmede daha etkili olduğu görülmüştür (19).

IBS hastalarına yaşam tarzı ve beslenme alışkanlıklarını değiştirilmesi önerilse de henüz kesin bir beslenme tedavisi bulunmamaktadır. Hastalar, semptomlarına göre bazı besinlerden çekinme veya daha fazla tüketme eğiliminde olabilmekte; çeşitli diyet yaklaşımlarını denemektedir (20). IBS hastalarının daha az/fazla tükettikleri besinler, yanlış beslenme davranışları, tedavi amaçlı kullandıkları takviyeler gibi ögeler sağlıklı bireylere göre farklılık gösterebilmektedir.

Bu çalışmamızda, IBS hastalarında daha sık gözlenen beslenme alışkanlarının incelenmesi ve sağlıklı bireylerin beslenme alışkanlıkları ile karşılaştırılması amaçlanmıştır. Böylece IBS hastalarının semptomlarını iyileştirebilecek beslenme alışkanları, besin ve takviye gibi önerilerde bulunulması hedeflenmiştir. 


\section{GEREÇ ve YÖNTEM}

\section{Araştırma Yeri, Zamanı ve Örneklem Seçimi}

$\mathrm{Bu}$ çalışma, Mart-Nisan 2020 tarihleri arasında online erişim ile yürütülmüştür. Bu çalışma için Üsküdar Üniversitesi Etik Kurulundan 61351342/2020-97 sayılı 27/02/2020 tarihli “Etik Kurul Onayı” alınmıştır.

Katılımcılar, IBS tanısı almış hastalardan ve herhangi bir sağlık sıkıntısı olmayan bireylerden oluşmaktadır. Çalışmanın dahil edilme kriterleri arasında; IBS hastaları için 18-65 yaş aralığında olunması, Roma IV kriterlerine göre IBS tanısı almış olması (1), herhangi bir konuda enerji ve/ veya besin alımını kısıtlayan diyet müdahalesi yapılmamış olması, herhangi bir psikiyatrik hastalığı olmaması, gebe, emziren ve engelli olunmaması koşulları aranmıştır. Kontrol grubu için dahil olma koşullarında 18-65 yaş aralığında olunması ve kronik bir hastalığı bulunmaması yer almıştır. Araştırmaya katılan kişilerden "Bilgilendirilmiş Gönüllü Onam Formu" onayı alınmıştır. Bu kriterlere uymayan katılımcılar çalışmaya dahil edilmemiştir.

\section{Verilerin Toplanması ve Değerlendirilmesi}

Araştırma, tanımlayıcı bir çalışma olup, veriler anket yardımıyla toplanmıştır. Çalışma için oluşturulan anket formunda bireylerin demografik özellikleri; kronik hastalık varlığı, IBS tanı süre ve semptomları, kullandıkları ilaçlar; antibiyotik, alkol kullanımı, sigara kullanımı, fiziksel aktivite durumu, beslenme alışkanlıkları ve besin tüketim sıklığı hakkında sorular yer almıştır. Beden kitle indeksi (BKİ), kişilerin belirttikleri boy uzunluğu (m) ve vücut ağırlığı (kg) değerleri kullanılarak hesaplanmıştır.

İstatiksel analizler için SPSS 25.0 istatiksel paket programı kullanılmıştır. İstatiksel olarak $p<0,05$ değeri anlamlı kabul edilmiştir.

\section{BULGULAR}

Katılımcıların yaş, ağırlık $(\mathrm{kg}), \mathrm{BKI}\left(\mathrm{kg} / \mathrm{m}^{2}\right)$, beslenme alışkanlıklarına dair bilgiler Tablo 1 'de verilmiştir. Çalışmaya vaka grubu için IBS tanısı alan 40 kişi ve kontrol grubu için sağlıklı 40 kişi katılmıştır. Vaka grubunun \%80'i kadın ve yaş ortalaması $35,2 \pm 11,0$ yıldır. Vaka grubunun ortalama vücut ağırlığ $167,0 \pm 11,7 \mathrm{~kg}$ ve BKİ ortalamas $24,7 \pm 3,9 \mathrm{~kg} / \mathrm{m}^{2}$ ' dir. Kontrol grubunda ise $\% 75$ 'i kadın ve yaş ortalaması $29,9 \pm 9,2$ yıldır. Ortalama vücut ağırlığ 1 $64,4 \pm 10,8 \mathrm{~kg}$ ve BKİ ortalamasi $22,9 \pm 2,9 \mathrm{~kg} / \mathrm{m}^{2}$ 'dir. Vaka grubunda IBS tanısı konma süresi ortalama $6,2 \pm 6,8$ yıldır.

Öğün sıklığına bakıldığında vakaların $\% 42,5$ 'i; kontrollerin $\% 35$ 'i günde 3 öğün tükettiğini belirtmiştir. IBS tanıs1 olan katılımcılara semptomları şiddetlendiren besinler sorulduğunda \%12,3'ü baklagil; \%11,3'ü kahve; \%9,4'ü kızartma; \%7,5'i gazlı içecekler ve \%4,7'si acıyı söylemiştir. Semptomları azaltan besinler sorgulandığında ise \%29,4'ü yoğurdu belirtmiştir.

IBS tanısına sahip olma durumuna göre tanımlayıcı özellikler karşılaştırılmıştır. Buna göre vaka grubunda yaş $(p=0,022)$ ve BKI $(p=0,018)$ istatiksel olarak anlamlı bir şekilde yüksek bulunmuştur. Vaka grubunun \%17,5’u probiyotik tüketirken; kontrol grubunda hiç kimsenin tüketmediği belirlenmiş, aradaki fark anlamlı bulunmuştur $(\mathrm{p}=0,018)$. Aynı şekilde laksatif kullanımı IBS tanısı alan hastalarda daha fazla görülmüş, bu fark istatiksel açıdan anlamlı bulunmuştur $(p=0,001)$. Çalışmada İBS tanısı alma durumu ile ağırlık, günlük uyku süresi, günlük su tüketimi, günlük çay tüketimi, günlük kahve tüketimi, cinsiyet, sigara ve alkol kullanımı, öğün sayısı, gıda hassasiyeti/alerjisi ve egzersiz yapma arasında istatistiksel açıdan anlamlı fark bulunmamıştır ( $\mathrm{p}>0,05$; Tablo 1$)$.

Katılımcılardan IBS tanısı alanların $\% 45$ 'i ve sağlıklı kontrollerin $\% 22,5$ 'i gün aşırı et, balık ve tavuk $(\mathrm{p}=0,036)$; İBS tanısı alanların \%60'1 ve sağl1klı kontrollerin \%90'1 her gün ekmek, tahil ve kuru baklagiller $(\mathrm{p}=0,023)$; İBS tanısı alanların $\% 47,5$ 'i haftada bir ve sağlıklı kontrollerin $\% 67,5$ 'i her gün yumurta $(\mathrm{p}=0,000)$ tükettiği saptandı. Tanı alma durumuna göre et, balık ve tavuk; ekmek, tahıl ve kuru baklagiller; yumurta tüketimi arasındaki fark istatistiksel olarak anlamlı bulundu. Çalışmada IBS tanısı alma durumu ile süt ürünleri $(\mathrm{p}=0,085)$, meyve, sebze $(\mathrm{p}=0,477)$, tereyăg 1 , margarin $(p=0,102)$ ve zeytinyağ 1 , siv1 yağ $(p=0,323)$ tüketim sıklığı arasında istatistiksel açıdan anlamlı bir fark bulunamadı (Tablo 2). 
Tablo 1. Irritabl bağırsak sendromu tanısına sahip olma durumu ile tanıtıcı özelliklerin karşılaştırılması

\begin{tabular}{|c|c|c|c|c|c|c|c|}
\hline & & \multicolumn{4}{|c|}{ İBS Tanısı } & \multirow{3}{*}{ F } & \multirow[b]{2}{*}{ p } \\
\hline & & \multicolumn{2}{|c|}{$\operatorname{Var}(n=40)$} & \multicolumn{2}{|c|}{ Yok $(n=40)$} & & \\
\hline Değişkenler & & \multicolumn{2}{|c|}{ Ort \pm SS } & \multicolumn{2}{|c|}{ Ort \pm SS } & & \\
\hline Yaş & & \multicolumn{2}{|c|}{$35,2 \pm 11,0$} & \multicolumn{2}{|c|}{$29,9 \pm 9,2$} & 2,861 & 0,022 \\
\hline Ağırlık (kg) & & \multicolumn{2}{|c|}{$67,0 \pm 11,7$} & \multicolumn{2}{|c|}{$64.4 \pm 10.8$} & 0,059 & 0,306 \\
\hline BKİ & & \multicolumn{2}{|c|}{$24,7 \pm 3,9$} & \multicolumn{2}{|c|}{$22,9 \pm 2,9$} & 2,205 & 0,018 \\
\hline Günlük uyku süresi (saat) & & \multicolumn{2}{|c|}{$7,2 \pm 1,3$} & \multicolumn{2}{|c|}{$6,9 \pm 1,0$} & 5,219 & 0,230 \\
\hline Günlük su miktarı (bardak) & & \multicolumn{2}{|c|}{$7,1 \pm 3,8$} & \multicolumn{2}{|c|}{$5,9 \pm 2,6$} & 6,912 & 0,099 \\
\hline Günlük çay miktarı (bardak) & & \multicolumn{2}{|c|}{$4,8 \pm 3,0$} & \multicolumn{2}{|c|}{$3,6 \pm 2,6$} & 0,179 & 0,089 \\
\hline Günlük kahve miktarı (bardak) & & \multicolumn{2}{|c|}{$2,2 \pm 1,5$} & \multicolumn{2}{|c|}{$1,9 \pm 1,1$} & 3,276 & 0,595 \\
\hline \multirow{2}{*}{ Tan1 Konma Süresi (y1l) } & & \multicolumn{2}{|c|}{$6,2 \pm 6,8$} & \multicolumn{2}{|c|}{$1-30$} & & \\
\hline & & $\mathbf{N}$ & $\%$ & $\mathbf{N}$ & $\%$ & $\mathbf{X}^{2}$ & p \\
\hline \multirow{2}{*}{ Cinsiyet } & Erkek & 8 & 20,0 & 10 & 25,0 & \multirow{2}{*}{0,287} & \\
\hline & Kadın & 32 & 80,0 & 30 & 75,0 & & 0,790 \\
\hline & Her ikisini de kullanırım & 3 & 7,5 & 3 & 7,5 & & \\
\hline & Her ikisini de kullanmam & 23 & 57,5 & 22 & 55,0 & & \\
\hline Sigara-Alkol Kullanımı & Sadece sigara kullanırım & 12 & 30,0 & 11 & 27,5 & 0,732 & 0,866 \\
\hline & Sadece alkol kullanırım & 2 & 5,0 & 4 & 10,0 & & \\
\hline & 1 öğün & 0 & 0 & 0 & 0 & & \\
\hline & 2 öğün & 11 & 27,5 & 10 & 25,0 & & \\
\hline & 3 öğün & 17 & 42,5 & 14 & 35,0 & & \\
\hline Öğ̈̈n Sayısı & 4 öğün & 5 & 12,5 & 10 & 25,0 & 4,067 & 0,397 \\
\hline & 5 öğün & 5 & 12,5 & 4 & 10,0 & & \\
\hline & 6 öğün & 2 & 5,0 & 0 & 0 & & \\
\hline & Yok & 31 & 77,5 & 39 & 97,5 & & \\
\hline & Ispanak & 1 & 2,5 & 0 & 0 & & \\
\hline & Süt & 2 & 5,0 & 0 & 0 & & \\
\hline & Mantar & 1 & 2,5 & 0 & 0 & & \\
\hline Gıda Hassasiyeti/Alerjisi & Domates & 1 & 2,5 & 0 & 0 & 8,914 & 0,350 \\
\hline & Zeytin & 1 & 2,5 & 0 & 0 & & \\
\hline & Çikolata & 1 & 2,5 & 0 & 0 & & \\
\hline & Fist1k & 1 & 2,5 & 0 & 0 & & \\
\hline & Yumurta & 1 & 2,5 & 1 & 2,5 & & \\
\hline & Evet & 7 & 17,5 & 0 & 0 & & \\
\hline Probiyotik Kullanımı & Hayır & 33 & 82,5 & 40 & 100,0 & 7,671 & 0,018 \\
\hline & Evet & 12 & 30,0 & 16 & 40,0 & & \\
\hline Egzersiz & Hayır & 28 & 70,0 & 24 & 60,0 & 0,879 & 0,348 \\
\hline & Evet & 10 & 25,0 & 0 & 0 & & \\
\hline Laksatif Kullanımı & Hayır & 30 & 75,0 & 40 & 100,0 & 11,429 & 0,001 \\
\hline
\end{tabular}

$\mathrm{F}=$ Student $\mathrm{T}$ Test; $\mathrm{x}^{2}=$ Kikare

Tablo 2. Irritabl bağırsak sendromu tanısına sahip olma durumu ile besin tüketim sıklığının karşılaştırılması

\begin{tabular}{|c|c|c|c|c|c|c|c|c|c|c|c|c|c|c|c|}
\hline \multirow[t]{2}{*}{ Besinler $(n=80)$} & \multirow[t]{2}{*}{ İBS Tanısı } & \multicolumn{2}{|c|}{ Hiç } & \multicolumn{2}{|c|}{$\begin{array}{c}\text { Ayda } \\
\text { Bir }\end{array}$} & \multicolumn{2}{|c|}{$\begin{array}{c}15 \text { Günde } \\
\text { Bir }\end{array}$} & \multicolumn{2}{|c|}{$\begin{array}{c}\text { Haftada } \\
\text { Bir }\end{array}$} & \multicolumn{2}{|c|}{$\begin{array}{l}\text { Gün } \\
\text { Assırı }\end{array}$} & \multicolumn{2}{|c|}{$\begin{array}{l}\text { Her } \\
\text { Gün }\end{array}$} & \multirow[t]{2}{*}{$\mathbf{X}^{2}$} & \multirow[t]{2}{*}{$\mathbf{p}$} \\
\hline & & $\mathrm{n}$ & $\%$ & $\mathrm{n}$ & $\%$ & $\mathrm{n}$ & $\%$ & $\mathrm{n}$ & $\%$ & $\mathrm{n}$ & $\%$ & $\mathrm{n}$ & $\%$ & & \\
\hline \multirow{2}{*}{ Süt ürünleri } & Var & 0 & 0 & 1 & 2,5 & 3 & 7,5 & 7 & 17,5 & 10 & 25,0 & 19 & 47,5 & \multirow{2}{*}{9,669} & \multirow{2}{*}{0,085} \\
\hline & Yok & 2 & 5,0 & 0 & 0 & 1 & 2,5 & 13 & 32,5 & 3 & 7,5 & 21 & 52,5 & & \\
\hline \multirow{2}{*}{ Et, balık, tavuk } & Var & 0 & 0 & 0 & 0 & 4 & 10,0 & 12 & 30,0 & 18 & 45,0 & 6 & 15,0 & \multirow{2}{*}{10,286} & \multirow{2}{*}{0,03} \\
\hline & Yok & 4 & 10,0 & 0 & 0 & 1 & 2,5 & 18 & 45,0 & 9 & 22,5 & 8 & 20,0 & & \\
\hline \multirow{2}{*}{$\begin{array}{l}\text { Ekmek, tahıl, kuru } \\
\text { baklagil }\end{array}$} & Var & 0 & 0 & 2 & 5,0 & 2 & 5,0 & 7 & 17,5 & 5 & 12,5 & 24 & 60,0 & \multirow{2}{*}{11,333} & \multirow{2}{*}{0,023} \\
\hline & Yok & 0 & 0 & 1 & 2,5 & 0 & 0 & 3 & 7,5 & 0 & 0 & 36 & 90,0 & & \\
\hline \multirow{2}{*}{ Yumurta } & Var & 1 & 2,5 & 1 & 2,5 & 2 & 5,0 & 19 & 47,5 & 9 & 22,5 & 8 & 20,0 & \multirow{2}{*}{29,126} & \multirow{2}{*}{0,000} \\
\hline & Yok & 4 & 10,0 & 0 & 0 & 0 & 0 & 2 & 5,0 & 7 & 17,5 & 27 & 67,5 & & \\
\hline \multirow{2}{*}{ Meyve, sebze } & Var & 0 & 0 & 1 & 2,5 & 1 & 2,5 & 9 & 22,5 & 9 & 22,5 & 20 & 50,0 & \multirow{2}{*}{4,525} & \multirow{2}{*}{0,477} \\
\hline & Yok & 2 & 5,0 & 1 & 2,5 & 2 & 5,0 & 8 & 20,0 & 4 & 10,0 & 23 & 57,5 & & \\
\hline \multirow{2}{*}{ Tereyağl, margarin } & Var & 4 & 10,0 & 6 & 15,0 & 4 & 10,0 & 7 & 17,5 & 5 & 12,5 & 14 & 35,0 & \multirow{2}{*}{9,185} & \multirow{2}{*}{0,102} \\
\hline & Yok & 5 & 12,5 & 2 & 5,0 & 6 & 15,0 & 6 & 15,0 & 14 & 35,0 & 7 & 17,5 & & \\
\hline \multirow{2}{*}{ Zeytinyă̆l, siviyağ } & Var & 2 & 5,0 & 2 & 5,0 & 3 & 7,5 & 7 & 17,5 & 26 & 65,0 & 0 & 0 & \multirow{2}{*}{4,672} & \multirow{2}{*}{0,323} \\
\hline & Yok & 0 & 0 & 0 & 0 & 0 & 0 & 4 & 10,0 & 10 & 25,0 & 26 & 65,0 & & \\
\hline
\end{tabular}

$\mathrm{X}^{2}=$ Kikare 


\section{TARTIŞMA}

Çalışmamızda, IBS tanısı alan hastalar ile sağlıklı bireylerin beslenme alışkanlıklarının karşılaştırılması amaçlanmıştır. Çalışmaya katılan IBS hastalarının \%80'i ve sağlıklı bireylerin $\% 75$ 'i kadınlardan oluşmaktadır. Genel olarak literatürde, IBS prevalansı kadınlarda daha yaygın görülmüştür $(21,22)$. Amerika'da yapılan bir çalışmada fonksiyonel gastrointestinal hastalıklara sahip katılımcılardan kadınların \%14,5'inde ve erkeklerin \%7,7'sinde IBS semptomları gözlenmiştir (23). Japonya'da online anket ile 30,000 kişi ile gerçekleştirilen bir çalışmada, abdominal şişkinlik ve abdominal doygunluk kadınlarda anlamlı olarak daha fazla görülmüştür (24). Bu çalışmada ise IBS tanısı alan kişilerin çoğunluğu kadınlardan oluşmaktadır. Ancak cinsiyete göre IBS tanısı alma durumu karşılaştırıldığında anlamlı ilişki bulunamamıştır ( $>>0,05)$. Kadınlarda daha fazla görülmesi ise cinsiyet hormonlarına, yemek yeme düzenine bağlı olabileceği bildirilmiştir (22, 25).

IBS'li ve sağlıklı katılımcıların BKİ ortalamaları ise sirasiyla $24,7 \pm 3,9 \mathrm{~kg} / \mathrm{m}^{2}$ ve $22,9 \pm 2,9 \mathrm{~kg} / \mathrm{m}^{2}$ 'dir. $\mathrm{Bu}$ çalışmada her iki grup için de katılımcıların BKİ değerleri normal aralıktadır. Obezite, IBS semptomları ve beslenme alı̧̧kanlıkları ile ilişkilendirilmektedir. Obez bireylerde besin alımının ve enerji tüketimi kontrol mekanizmalarının düzensiz olması IBS semptomlarını artırabilmektedir (26). Amerika'da yapılan bir çalışmada yüksek BKI'ye sahip bireylerde kusma, üst abdominal ağrı, şişkinlik ve ishal daha s1k yaşanmış, bu fark anlamlı bulunmuştur (12). Obezite, IBS'de fonksiyonel düzensizlik oluşturan bozulmuş mikrobiyota bileşimi ile ilişkili olabilmektedir. Aynı zamanda IBS'de bağırsağın mikrobiyolojik, hormonal ve besleyici yönlerinin değişmesiyle obeziteyi tetikleyebileceği de düşünülmektedir (27). Obeziteden kaynaklı bağırsak değişiklikleri, uzun yıllar obez olan orta yaşlı bireylerde daha çok görülebilmektedir (28). Obezite ve IBS arasındaki neden-sonuç ilişkisi halen tam açıklanamazken; sağlkklı beslenme alışkanlıkları ve egzersiz tedavisinin iki hastalık için de etkili olduğu bildirilmiştir (27).

Kilolu bireylerde daha fazla gözlenen düzensiz yemek yeme ve hızlı yeme alışkanlıkları, IBS riskinin daha yüksek olmasıyla ilişkili bulunmuştur. $\mathrm{Bu}$ çalışmada öğün sıklığı değerlendirildiğinde vakaların $\% 42,5{ }^{\prime} \mathrm{i}$; kontrollerin \%35'i günde 3 ögün tükettiğini belirtmiş, ancak fark anlamlı bulunmamıştır. Aynı zamanda günlük çay, kahve ve su tüketimine bakıldığında IBS tanısı alan ve sağlıklı bireyler arasında herhangi bir fark saptanmamıştır.
Ancak bir çalışmada yemek esnasında fazla sıvı alımının koruyucu bir şekilde IBS ile ilişkili olduğu gösterilmiştir (25). Buna karşın, çalışmamıza benzer olarak, günlük su tüketimi ile IBS olma olasılığı arasındaki ilişkiyi inceleyen bir çalışmada anlamlı bir ilişki bulunamamıştır. Aynı çalışmada, Roma III kriterlerine göre karışık tip IBS (hem diyare hem de konstipasyon içeren) tanısı alan hastalar ile 8 bardak/gün'den fazla su tüketimi arasında önemli bir ilişki gözlenmiştir (29). Bu çalışmaya göre IBS'li hastaların yemek sırasında fazla sıvı alımını azaltmaları ancak günlük ihtiyacı kadar sıvı almaları önerilmiştir.

$\mathrm{Bu}$ çalışmada et grubu, tahıl grubu ve yumurta tüketimi ile IBS tanısı alma arasında fark bulunmaktadır. IBS hastalarının et, balık ve tavuk tüketimi gün aşırıya eğilimliyken; ekmek, tahıl ve kuru baklagiller ile yumurta tüketimi haftada bire eğilimli olduğu görülmüştür. Buna karşın sağlıklı bireylerin çoğu bu besinleri genellikle her gün tükettiğini bildirmiştir. Simren ve ark'nın yaptığı çalışmada IBS semptomlarından gaz problemleri ve abdominal ağrı, yemek tüketimi ile ilişkili bulunmuştur. Karbonhidrat, yağlı yiyecekler, kahve, alkol ve acı baharatlı besinlerin semptomlara daha sık neden olduğu gözlenmiştir (30). IBS hastalarının, tüketmeye çekindikleri besinleri inceleyen bir çalışmada; GI semptomlardan dolayı ketçap, hamur, gazlı içecek, üzüm, tereyağı tüketiminden kaçınma olasılığı daha yüksek bulunmuştur (31).

Diyetle alınan FODMAP miktarının IBS ile ilişkili olabileceği düşünülmektedir. IBS hastalarında FODMAP içermeyen diyet müdahalesinin semptomlarda iyileşmeye neden olduğu, özellikle abdominal şişkinlik, yorgunluk ve bulantı semptomlarında iyileşme gözlendiği görülmüştür (32). Başka bir çalışmada FODMAP diyetinin, IBS semptom şiddetini azaltmada olumlu etkileri olduğu; yaşam kalitesini artırdığı saptanmıştır (33). IBS semptomları üzerine yapılan randomize kontrollü diğer bir çalışmada düşük FODMAP diyeti ile geleneksel diyet tedavisi karşılaştırıldığında; her iki diyetin de semptomları azalttığı ancak düşük FODMAP diyetinin bazı spesifik IBS semptomlarında daha etkili olduğu bildirilmiştir (12). Ancak fermente edilebilir karbonhidrat tüketiminin azalmasına bağlı olarak düşük bifidobakteri konsantrasyonu gözlenmiştir. $\mathrm{Bu}$ durum düşük FODMAP diyetinin bağırsak mikrobiyotası üzerine olumsuz etkileri olabileceğini göstermiştir (17).

Çalışmamızda IBS'li katılımcıların \%17,5'i probiyotik kullandığı ve sağlıklı kontrollerden ise hiç kimsenin probiyotik kullanmadığı saptanmıştır, bu fark anlamlı bulunmuştur $(p<0,05)$. Kolon mikroflorasına olumlu 
etkileri bulunan probiyotik, prebiyotik ve sinbiyotikler IBS semptomlarını da olumlu etkileyebilmektedir. Probiyotik ve sinbiyotik tedavisi alan IBS' li bireylerde abdominal şişkinlik, konstipasyon ve postprandiyal şişkinlik semptomlarında iyileşme gözlenmiştir (34). Prebiyotik tedavisi dışk1 kıvamını değiştirerek gaz ve şişkinlik semptomlarını azaltmaktadır (35). Tek veya çok suşlu probiyotiklerin etkisini araştıran bir meta-analizde, bazı spesifik probiyotik kombinasyonlarının kalıcı IBS semptomları riskini ve gaz şikayetini azalttığı $(p<0,05)$; ancak şişkinlik semptomuna etkili olmadığı görülmüştür (36). Bazı IBS semptomlarının iyileştirilmesinde probiyotik kombinasyonlarının kullanımı tavsiye edilebilmektedir.

Çalışmamızın bazı sınırlılıkları bulunmaktadır. Birincisi, çalışma kapsamının genişletilmesi açısından normal ağırlıkta olan IBS hastalarının yanı sira obez olan hastaların dahil edilmesi uygun olabilirdi. İkincisi, örneklem büyüklüğü daha yüksek tutulabilirdi. Üçüncüsü, IBS tanısı alan hastalar alt gruplarına, semptomların şiddeti ile sıklığına göre sınıflandırılabilirdi. Çalışmamızın belirli bir zaman aralığında yürütülmüş olması bu sınırlılıklar ile sonuçlanmıştır. Gelecekte yapılacak çalışmalarda daha geniş ve çeşitli bir örneklem ile günlük besin tüketiminin ve spesifik diyet yaklaşımlarının, IBS semptomlarının şiddetine ve sıklığına etkileri incelenebilir.

Sonuç olarak, çalışmamız IBS tanısı almış bireylerin bazı beslenme alışkanlıklarının sağlıklı bireylere göre farklılık gösterdiğini kanıtlamıştır. IBS hastalarının öğünlerinin düzenli olması, yemek sırasında sıvı tüketmemesi ve probiyotik kullanımı gibi beslenme alışkanlıkları hastalığın prognozunu olumlu yönde etkileyebileceği gösterilmiştir. Aynı zamanda IBS hastalarının fazla kilolu/obez olmaya yatkınlıkları olabileceği gösterilmiştir. Karbonhidratlı ve yağlı besinler, acı baharatlar, FODMAP içeren besinler gibi belirtileri tetikleyebilecek ögelerin diyetten çıkarılması IBS semptomlarını hafifletebilmektedir.

\section{KAYNAKLAR}

1. Kaya M, Kaçmaz H. Roma IV kriterlerine göre fonksiyonel barsak hastalıklarının yeniden değerlendirilmesi. Güncel Gastroenteroloji. 2016; 20(4): 393-407.

2. El-Salhy M, Gundersen D. Diet in irritable bowel syndrome. Nutrition journal. 2015; 14(1): 1-11.

3. Oka P, Parr H, Barberio B, Black CJ, Savarino EV, Ford AC. Global prevalence of irritable bowel syndrome according to Rome III or IV criteria: a systematic review and metaanalysis. The Lancet Gastroenterology \& Hepatology. 2020; online.
4. Karabayraktar T, Ahıshalı E, Dolapçığlu C. Obezite ve İritabl Bağırsak Sendromu. J Kartal TR, 2014; 25(2): 12732.

5. Ozer M, Bengi G, Colak R, Cengiz O, Akpinar H. Prevalence of irritable bowel syndrome-like symptoms using Rome IV criteria in patients with inactive inflammatory bowel disease and relation with quality of life. Medicine. 2020; 99(19): e20067.

6. Canavan C, West J, Card T. The epidemiology of irritable bowel syndrome, Clinical Epıdemiology. 2014; 6: 71-80.

7. Mullin GE, Shepherd SJ, Chander Roland B, Ireton-Jones C, Matarese LE. Irritable bowel syndrome: contemporary nutrition management strategies. Journal of Parenteral and Enteral Nutrition, 2014; 38(7): 781-799.

8. Creed F. Review article: the incidence and risk factors for irritable bowel syndrome in population-based studies. Aliment Pharmacol Ther. 2019; 50: 507-516.

9. Flacco ME, Manzoli L, De Giorgio R, Gasbarrini A, Cicchetti A, Bravi F, Ursini F. Costs of irritable bowel syndrome in European countries with universal healthcare coverage: a meta-analysis. 2019; 23: 2986-3000.

10. Tap J, Derrien M, Törnblom H, Brazeilles R, Cools-Portier S, Doré J, Störsrud S, Le Nevé B, Öhman L, Simrén M. Identification of an Intestinal Microbiota Signature Associated With Severity of Irritable Bowel Syndrome. Gastroenterology 2017; 152: 111-123.

11. Simrén M, Törnblom H, Palsson OS, Whitehead W. Management of the multiple symptoms of irritable bowel syndrome. Lancet Gastroenterol. Hepatol. 2017; 2: 112-122.

12. Algera J, Colomier E, Simrén M. The dietary management of patients with irritable bowel syndrome: a narrative review of the existing and emerging evidence. Nutrients. 2019; 11(9): 2162.

13. Nilholm C, Larsson E, Roth B, Gustafsson R, Ohlsson B. Irregular dietary habits with a high intake of cereals and sweets are associated with more severe gastrointestinal symptoms in IBS patients. Nutrients. 2019; 11(6): 1279.

14. Özdemir M, Perktaş G. İrritable Bağırsak Sendromunda Diyet. Güncel Gastroenteroloji. 2016; 20(3): 274-279.

15. Moayyedi P, Quigley EM, Lacy BE, Lembo AJ, Saito YA, Schiller LR, Soer EE, Spiegel BM, Ford AC. The effect of fiber supplementation on irritable bowel syndrome: A systematic review and meta-analysis. Am. J. Gastroenterol. 2014; 109: 1367-1374.

16. Müller M, Canfora EE, Blaak EE. Gastrointestinal Transit Time, Glucose Homeostasis and Metabolic Health: Modulation by Dietary Fibers. Nutrients 2018: 10; 1-18.

17. Staudacher HM, Lomer MCE, Farquharson FM, et al. A diet low in FODMAPs reduces symptoms in patients with irritable bowel syndrome and a probiotic restores bifidobacterium species: a randomized controlled trial. Gastroenterology. 2017;153(4):936-947.

18. Hill C, Guarner F, Reid G. Expert consensus document. The International Scientific Association for Probiotics and Prebiotics consensus statement on the scope and appropriate use of the term probiotic. Nat Rev Gastroenterol Hepatol. 2014;11(8):506-514. 
19. Niu HL, Xiao JY. The efficacy and safety of probiotics in patients with irritable bowel syndrome: Evidence based on 35 randomized controlled trials. International Journal of Surgery. 2020: 75; 116-127.

20. Dimidi E, Whelan K. Food supplements and diet as treatment options in irritable bowel syndrome. Neurogastroenterology \& Motility. 2020; 32(8): e13951.

21. Okami Y, Kato T, Nin G, Harada K, Aoi W, Wada S. Lifestyle and psychological factors related to irritable bowel syndrome in nursing and medical school students. J Gastroenterol. 2011; 46: 1403-1410.

22. Mulak A, Tache Y, Larauche M. Sex hormones in the modulation of irritable bowel syndrome. World $\mathrm{J}$ Gastroenterol. 2014; 20: 2433-2448.

23. Camilleri M. Sex as a biological variable in irritable bowel syndrome. Neurogastroenterology \& Motility, 2020; e13802.

24. Kosako M, Akiho H, Miwa H, Kanazawa M, Fukudo S. Impact of symptoms by gender and age in Japanese subjects with irritable bowel syndrome with constipation (IBS-C): a large population-based internet survey. Biopsychosoc Med. 2018; 12: 12.

25. Zaribaf F, Keshteli AH, Esmaillzadeh A, Saneei P, Feizi A, Daghaghzadeh H, Adibi P. Empirically derived dietary habits are associated with irritable bowel syndrome. European journal of clinical nutrition. 2018; 72(11): 1537-1547.

26. Saneei P, Esmaillzadeh A, Keshteli AH, Feizi A, FeinleBisset C, Adibi P. Patterns of dietary habits in relation to obesity in Iranian adults. Eur J Nutr. 2016; 55: 713-728.

27. Pugliese G, Muscogiuri G, Barrea L, Laudisio D, Savastano S, Colao A. Irritable bowel syndrome: a new therapeutic target when treating obesity?. Hormones. 2019; 18(4): 395399.

28. Talley NJ, Howell S, Poulton R. Obesity and chronic gastrointestinal tract symptoms in young adults: a birth cohort study. Am J Gastroenterol. 2004; 99: 1807-1814.
29. Salari-Moghaddam A, Hassanzadeh Keshteli A, Esmaillzadeh A, Adibi P. Water consumption and prevalence of irritable bowel syndrome among adults. Plos one. 2020; 15(1): e0228205.

30. Simrén M, Månsson A, Langkilde AM, Svedlund J, Abrahamsson H, Bengtsson U, Björnsson ES. Food-related gastrointestinal symptoms in the irritable bowel syndrome. Digestion. 2001; 63(2): 108-115.

31. Soltani S, Keshteli AH, Esmaillzadeh A, Adibi P. Food Item Avoidance of Patients with Irritable Bowel Syndrome Compared with Healthy People. Archives of Iranian medicine. 2019; 22(7): 369-375.

32. Zhan YL, Zhan YA, Dai SX. Is a low FODMAP diet beneficial for patients with inflammatory bowel disease? A meta-analysis and systematic review, Clinical Nutrition, 2018; 37(1): 123-129.

33. Ustaoğlu $T$, Tek NA, Yıldırım AE. İrritabl Bağırsak Sendromunda (IBS) FODMAP Diyetinin İBS Semptomları, Beslenme Durumu ve Yaşam Kalitesi Üzerine Etkilerinin Değerlendirilmesi. Beslenme ve Diyet Dergisi. 2020; 1-12.

34. Baştürk A, Artan R, Yılmaz A. Efficacy of synbiotic, probiotic, and prebiotic treatments for irritable bowel syndrome in children: A randomized controlled trial. The Turk1sh Journal Of Gastroenterology. 2016; 27: 439-443.

35. Silk DB, Davis A, Vulevic J, Tzortzis G, Gibson GR. Clinical trial: the effects of a transgalactooligosaccharide prebiotic on faecal microbiota And Symptoms İn İritable Bowel Syndrome. Alımentary Pharmacology \& Therapeutıcs. 2009; 29(5): 6508-6518.

36. Ford AC, Harris LA, Lacy BE, Quigley EMM, Moayyedi P. Systematic review with meta-analysis: the efficacy of prebiotics, probiotics, synbiotics and antibiotics in irritable bowel syndrome. Aliment Pharmacol Ther. 2018;48(10):1044-1060. 